\title{
Moving conceptual boundaries: so what?
}

\section{Chesterman, Andrew Peter Clement}

Routledge

2018-09-03

Chesterman , A P C 2018, Moving conceptual boundaries: so what? in H V Dam , M N

Brøgger \& K K Zethsen (eds), Moving Boundaries in Translation Studies . 1st Edition edn , Routledge , London , pp. 12-25 . https://doi.org/10.4324/9781315121871

http://hdl.handle.net/10138/312683

https://doi.org/10.4324/9781315121871

unspecified

acceptedVersion

Downloaded from Helda, University of Helsinki institutional repository.

This is an electronic reprint of the original article.

This reprint may differ from the original in pagination and typographic detail.

Please cite the original version. 
Moving conceptual boundaries: so what?

Andrew Chesterman

[2018c Moving conceptual boundaries: so what? In H. V. Dam, M. N. Brøgger and K. K. Zethsen (eds), Moving Boundaries in Translation Studies. London: Routledge, 12-25.]

\begin{abstract}
In Translation Studies, there are frequent proposals for conceptual innovation: new concepts, new distinctions, new superordinate categories, new taxonomies, new ways of seeing things, new metaphors. All these are viewed here as interpretive hypotheses. As such, they cannot be empirically falsified, but they nevertheless can and should be tested pragmatically, in terms of costs and benefits and consequences, and compared to alternatives. Some recent proposals concerning new conceptual boundaries are discussed. Conceptual arguments can sometimes be framed in misleading factual rhetoric, giving rise to non-desirable consequences in the form of fallacious inferences.
\end{abstract}

Keywords: conceptual analysis, categories, interpretive hypotheses, hermeneutics

\title{
Introduction
}

Moving conceptual boundaries means conceptual innovation. One aspect of conceptual innovation is the way we can divide up 'stuff' differently, to form and name new categories. A category collects bits of stuff that seem similar enough in given respects to count as one group, for a given purpose, so that we can generalize, overlooking less relevant differences within the group (see Ellis 1993). Creating new categories may have empirical consequences. Indeed, if there seem to be no such consequences, one wonders whether the conceptual innovation has any added value.

Another aspect of conceptual innovation is the way it can exploit a different kind of similarity, having to do with metaphorical associations between different phenomena which belong to different categories. We can see something "as" something else, as when we see translation "as" performance, or bridge-building, or whatever. There is obvious overlap between these two aspects of conceptual innovation, but I will discuss them separately here, for clarity of presentation.

I start by exploring the first kind of innovation, and suggest four ways in which it works, with some illustrative examples from Translation Studies. 


\section{Creating new categories}

\section{Platypus concepts}

"Platypus concepts" is my name for the kind of new concept that is proposed when a new empirical phenomenon is confronted. When the platypus was first discovered, zoologists apparently could not place it within any existing species category, so had to invent a new one, and a new name. Platypus means 'flatfooted'. The Latin scientific name became Ornithorhyncus anatinus, which means 'duck-like bird-snout'. Hence the animal's current English name "duck-billed platypus". - Here are some illustrative recent examples of such concepts in Translation Studies, randomly collected from work that has come my way recently.

Ad-hocracies. The term refers to temporary groups or associations of amateur translators or "citizen translators" working online (Pérez-González 2014). I applaud the neat term, for a genuinely new phenomenon, but I wonder if its potential sense is too broad, covering more than just translators. (We shall return to this general terminological issue of the relative usefulness of broad vs narrow concepts below.)

Fansubbing. This has become a useful new coinage for a new practice - non-professional subtitling done by fans of the film or TV programme in question - that can be studied as a particular type of translation.

Scanlation (also scanslation). This is defined as "the scanning, translation, and editing of comics from a language into another language. Scanlation is done as amateur work and is nearly always done without express permission from the copyright holder" (https://en.wikipedia.org/wiki/Scanlation.) The texts in question are mainly Japanese comics (manga) or Chinese comics (manhua). This term also seems to be justified, for another translation type corresponding to a new practice.

Transfiction. This is not a new practice, but a new term for grouping (i.e. lumping together - see below) a variety of translational phenomena into a single category as a research topic. Transfiction means the fictional, imagined representation of translators and interpreters and their practice, e.g. in novels or films. (See Kaindl and Spitzl 2015.) Surely a useful term, and transparent enough in English after the first mention. 
Translanguaging. This term (itself a translation from Welsh) derives from work on bilingual education in Wales, and has come to cover the practical and pedagogical use of two or more languages in the same context. (See e.g. Lewis et al. 2012.) It is obviously related to notions such as code-switching and passive bilingualism, but the idea also recalls the older sociolinguistic concept of a community's linguistic (or verbal) repertoire (Gumperz 1964), which can include items from more than one dialect or language. The scope of the translanguaging concept extends into the cognitive domain of individuals. The term, with the conceptualization behind it, seems to have become well rooted, so it evidently serves its purpose.

Translatorship. The coinage (Paloposki 2016) refers to a translator's social role, not the psychological habitus but the occupational profile. For instance, historically, many Finnish translators have been teachers, writers, or priests. However, there is a problem here: the term "multiple translatorship" was earlier coined by Jansen and Wegener (2013) with a different sense: to refer to the various agents that may be involved in producing and mediating translated literature. Outi Paloposki, who was aware of this earlier usage, has suggested to me (personal communication) that we might need a way of describing the status of words that seem to be on their way to becoming stabilized as "terms" - degrees of "termness", from vague and varied to more fixed. The term "translatorship" does not yet seem to have reached stable "termness", as two different senses are current. Terms with clearly different senses do not make for good terminology. Recall the problem of the two different senses of "adequacy" in Translation Studies. One is Toury's sense, 'adherence to source norms', as opposed to acceptability, defined as 'subscription to norms originating in the target culture' (Toury 1995: 56-57). The other is the skopos-theory sense, 'adequate to the skopos' (Reiß and Vermeer 1984: 139) or 'adequate to the brief' (Nord 1997: 35).

Translation space. The term comes originally from work by Michael Cronin (e.g. 2006: 68) and Sherry Simon (2012), but again meanings slightly vary in the usage of different scholars. Cronin wrote of public space in migrant societies as translation space (note: here the term is used as a mass noun), where all kinds of translation-related activities are going on. Kaisa Koskinen (2014) has studied a whole city as a translation space (note: a count noun). Pekka Kujamäki's use of the term (in Kujamäki and Footit 2016) in his research on wartime interpreting is slightly different again: here, the term designates an area where at first sight there is no evidence of translation, but we infer there must be, so let us look more closely. The term is clearly trending: there is a new journal called Translation Spaces, which expands the meaning of this term to include cognitive research and other disciplines too (see https://benjamins.com/catalog/ts $>$ Catalog $>$ Journals \& Yearbooks $>$ TS). It has evidently become a very productive concept, despite a not-yet-quite-fixed meaning. For a recent study, see Probirskaja (2017), where the space concerned is the train between Helsinki and St. Petersburg. 
Word translation entropy. This is, roughly, the probability of a given target-language item being selected by a given set of translators for a given source-text item. I.e. it is a measure of predictability (and thus variation). Translation entropy is assumed to increase when the number of translators of a given item increases, and it also depends on the kind of item in question. My source for this useful concept and its term is Carl et al. (2016: see sections 2.4.7 and 10.2).

\section{Splitter concepts}

In lexicography, a splitter is someone who likes to divide related concepts into different entries, whereas a lumper prefers to group them under a single entry (for the background, see

https://en.wikipedia.org/wiki/Lumpers_and_splitters). Splitters focus on differences, lumpers on similarities. Lovelock's hypothesis that we can conceptualize our planet as a single organism, Gaia, is a classic example of an influential lumping concept (see e.g.

https://en.wikipedia.org/wiki/Gaia hypothesis). Splitting is illustrated by the fate of Pluto, which used to be classified as a planet, but has now been demoted to dwarf status, as the "planet" concept was split (in 2006) into planets proper, dwarf planets and minor planets. This was decided by an institution, the International Astronomical Union, which was deemed to have the authority to do so. There is no such internationally recognized authority in TS, so our literature is full of proposals and debates about lumping and splitting, and how they might affect taxonomies. It is striking, for instance, that we have no generally agreed taxonomy of translation types, or translation solution types, although many have been proposed. (For a critical survey of some of these latter proposals, see Gambier 2008.) And we do not even have a generally agreed definition of translation itself!

TS has a long tradition of binary splits, from Cicero via Schleiermacher to Venuti and many others. It is worth noting that a binary distinction between $\mathrm{X}$ and $\mathrm{Y}$ does not necessarily mean that both $\mathrm{X}$ and $\mathrm{Y}$ are natural kinds. One, or both, might be a heterogeneous mix - this latter is usually the case in TS. I argue, however, that the key issue here is the importance of weighing up the pros and cons of being able to make generalizations, claims, hypotheses at different levels of generality or scope. This is a question of selecting the best conceptual tool for a given methodological purpose, not of formulating something factual about empirical reality. Some examples follow.

Interpretive use vs descriptive use (see Gutt 1990: 146-149, and Gutt 1991). This split distinguishes two kinds of language use. First, an utterance may aim to interpret another utterance, where the point is to interpretively resemble another utterance, as in reported speech or in translation "proper". And second, an 
utterance, in another language, may aim to describe the same state of affairs already described in the first utterance. The former type, for Gutt, defines translation proper, while the latter type, comprising all kinds of multilingual descriptions, is excluded from this category, and thus from Gutt's concept of translation. The problem with this split is, as many have commented, that it excludes a great deal of what many translators actually do. Compare e.g. the skopos approach, which is a lumper one. House's (1981) distinction between a translation and a version (where the target text is culturally adapted, filtered) is a similar splitter concept, and one not accepted by all scholars for the same reason that Gutt's split has been criticized: it reduces the range of what can then be called a translation. But under what circumstances might the benefit of such a split outweigh its disadvantages? It depends on the research question.

Cislation vs translation. Cislation is Igor Grbić's term (2011) for taking the reader into the source culture.

I would retain the term translation and take its literal meaning of "carrying over" as denoting carrying the text to the other side, thither, to the reader of the translation and his particular world [...] By using the opposite Latin prefix I suggest the term cislation, meaning carrying the reader - not the text - hither, cis, into the world inhabited by the particular work in question. (Grbić 2011: 3)

This interpretation thus places the cislating agent in the source culture, not the target culture. However, the same term has also been recently proposed by another scholar, with a totally different meaning (a difference much more significant than the one mentioned above concerning translatorship). This second proposal has to do with the ongoing argument about intralingual translation (see e.g. Zethsen 2009). Brian Mossop (2016) suggests that:

[i]ntralingual rewording should be called something else [i.e. not translation], and I suggest cislation: cis is a Latin preposition meaning 'on this side, on the near side', as opposed to trans, one meaning of which is 'on the far side'. So translation is carrying a message to the far side of a language border, whereas cislation is carrying a message to a new place while staying on 'this side' of the border. (Mossop 2016: 2)

Both proposals about cislation thus reduce the scope of the term "translation". But, as always, we need to weigh up the pros and cons of when a split here would be more useful than a lumping. When would differences between intralingual and interlingual translation be more relevant to a research project than their similarities (apart from the obvious case where the research question is indeed to investigate what differences there might be)? Compare Jakobson's (1959) tripartite distinction, with its much-discussed, rather ambiguous implications: was Jakobson at heart a splitter, implicitly separating "translation proper" from intralingual rewording and intersemiotic transmutation, or a lumper, including all his three types under one wide concept? 
The debate on intralingual translation illustrates some of the ways in which conceptual argument is carried on. Splitters like to point out significant differences between interlingual and intralingual translation, while lumpers prefer to highlight significant similarities or family resemblances. Splitters may give examples of possible "borderline cases", and appeal is made to preferred interpretations of other relevant concepts, such as "lingua", in this case, or the invariance-oriented activity that Mossop calls “equivalencing" (Mossop 2016: 7-11). Splitters would do well to list the significant research questions or hypotheses or generalizations that could be best formulated in terms of a split concept, and lumpers likewise for a more general concept. The question is thus not which definition is correct, but: for what purposes might a splitter or lumper definition be useful?

Übersetzung vs Bearbeitung. This distinction between two main activities performed by translators derives from Schreiber (1993), and has been followed up by others, including Mossop (2016). It separates invariance-oriented activities from variance-oriented ones (Bearbeitung, transediting). This conceptual split certainly suggests many interesting research questions concerning the different time distributions of these two activities in the case of different text types, translator types, etc. In Schreiber's original terminology, it is perhaps unfortunate that one of the two forms of work is given the term "Übersetzung", which, as we have seen in other cases above, limits the scope of this very general term.

Stable vs unstable source texts. Many scholars have deconstructed the notion of a single translator as a universal characteristic, splitting it into a set of different agents who may all contribute to a final translation: not just editors and terminologists and revisers, but also teams and groups of translators. The idea of a single source text has similarly been widely criticized as being far from universally applicable. Hernández Guerrero (2009: 43-46) proposed a split between stable and unstable source texts that seems to be useful, although there is surely a fuzzy border between the two. Unstable source texts are e.g. medieval manuscripts, some kinds of modern news articles (as opposed to editorials, which are more stable), and online texts that are constantly updated. Stable texts were originally associated with the advent of printing. Unstable texts may be more liable to be transedited (Valdeón 2015: 442) - an example of a split having empirically testable consequences.

Beyond binary splits, of course, we get more complex taxonomies, with more distinctions and more categories and subcategories. One asks again: for what purpose is a given subcategory proposed? The further down one goes into a taxonomy, the more important such a pragmatic justification seems to become. 
Lumper concepts

When might a lumper concept be more useful than a splitter one? If you are interested in higher-level generalizations, you go for lumpers. If you are more interested in lower-level particularities, you prefer splitters. One manifestation of this difference is seen in the arguments one sometimes sees between those who prefer a wide definition of some term and those who prefer a narrower definition. Style, for instance, can be taken narrowly as meaning the linguistic fingerprint of an individual writer, or widely in terms of the whole set of linguistic/poetic norms and conventions prevalent at a given time and place. Here are some TS examples.

Translationswissenschaft. This useful term was popularized by Vermeer and Reiß, to combine Übersetzen and Dolmetschen, and has become widely adopted in German-speaking publications. In English, some scholars have distinguished between translation and Translation with a capital, where the latter includes interpreting.

Constrained communication. This term comes from Lanstyák and Heltai (2012): in the context of investigating so-called universals of translation, they set up a category that is more general than translation, including all kinds of bilingual communication. Their claim is that many tendencies found in translation are also found in other kinds of what they called constrained communication (e.g. constrained by the level of the speaker's second-language competence). A similar argument is found in Ulrych's work (e.g. 2009) on 'mediated discourse', another category that includes more than just translation.

Sway. This is the term used by Robinson (2011) to denote all kinds of collective influence that affect a translator's decisions, such as norms, ideology, habits, prevailing narratives, and the like. I'm not sure whether having such a general cover-term really helps us to analyse the various causes of translator decisions; we shall see in time, whether the terminological suggestion catches on.

Voice. Some scholars have recently begun to give this term a new superordinate meaning, to include several different senses, both textual (such as heteroglossia, as in Bakhtin 1981) and contextual (such as the voices of different translation agents, e.g. as seen in paratexts, interviews etc.). Will this merging of senses bring new generalizations, concerning e.g. identity and power? For some evidence, see e.g. Alvstad (2013), and Taivalkoski-Shilov and Suchet (2013). 
Translation itself is of course a quintessential lumper concept, covering an ever-expanding range of activities, like the increasingly fragmented interdiscipline of Translation Studies. Both terms serve to maintain institutions and thus fulfil social and cultural purposes. However, there have also been major proposals that the whole field of Translation Studies should be lumped under some more general discipline such as communication studies (Gutt 1991) or, more recently systemic studies (Marais 2014: see Halverson 2015). Such lumpings may indeed be valuable for certain research questions, but for others it makes more sense to use more specific concepts. The value of exploring more general conceptualizations of translation is illustrated by Ella Vihelmaa's work on the translation of birdsong, i.e. on how birdsong is described in language. She wants to extend the notion of translation even further than Jakobson's intersemiotic type, to include interspecies translation as well. This extension is not to be taken metaphorically, like the use of "translation" in biology etc. Vihelmaa demonstrates how current TS concepts can bring a deeper understanding of human responses to birdsong, and to the natural environment in general. So far at least, no new term has been proposed for this "traduction en sens large" (she works in French and Finnish: see Vihelmaa 2015 for an online article on the topic in Finnish, but with many references to work in other languages).

\section{Rebranding concepts}

Here we are dealing with cases where a new term is given to an existing concept. Such rebranding is often initiated by industry, not academia. Rebranding does not necessarily alter the conceptual map as such (if the concept itself remains the same), but it does usually change connotations, associations and attitudes, and the balance of power, and can have economic consequences too. But the conceptual map itself may also be changed, as when a new hierarchical classification of a family of related concepts is proposed. Recall, for instance, the rebranding of Translation Studies that took place in the 1970s, when it shifted (or more accurately: was shifted, deliberately) from being seen as a discipline to promoting itself as an interdiscipline. Not all attempts to rebrand the field are successful. For instance, Holz-Mänttäri (1984) proposed new terms for key translation concepts (such as Botschaftsträger 'message-carrier' instead of $T e x t$ ) but they never really caught on, although her general functional approach was highly influential.

Localization is a classic example of rebranding, and shows how the notion of translation can be downgraded to a small corner of a rebranded larger practice, in order to highlight something presented as radically new, for commercial reasons. The localization industry does not see localization as one type of translation, unlike the view of many TS scholars. 
Transcreation is another example of evidently quite successful rebranding. The term refers to marketing and website translation, often multimodal, and has begun to make its way from the industry into academia. In a special issue of CULTUS on the topic of transcreation, Munday writes:

the New York-based company Transcreation Services, for instance, claims that the distinction of transcreation lies in "capturing the desired persuasive or emotive effect" of the source text and is "usually" (but not exclusively) used for the translation of advertising, marketing material and the like. (Gambier and Munday 2014: 20)

This view thus makes "capturing the desired persuasive or emotive effect" an extra service, beyond translation proper, to be paid for as something extra. But very few TS scholars, I imagine, would agree that achieving an appropriate effect is something outside translation proper! The case of transcreation certainly shows something about clients' perceptions of how limited "translation" is. Among other things, "transcreation" unfortunately also implies that ordinary translators do not need to be creative. On the positive side, one translator informed me not long ago that when she had a job that could be billed as "transcreation" she could triple the price... So the term evidently has its uses.

Universals can be seen as another example of rebranding - in this case, the rebranding of the basic notion of a (widespread) tendency. This term was first popularized in the 1990s by Mona Baker and others, and was perhaps selected in order to exploit associations with the more established concepts of linguistic universals, or behavioural universals in anthropology. But the term is actually rather misleading, as many have pointed out. Calling features (hypothetically) universal meant that hypotheses risked being interpreted as applying literally to "all translations", so they could be proved false by even a single example of counter-evidence. Formulations in terms of general tendencies of course need an explicit definition of what counts as a tendency, if they are to be falsifiable.

An interesting case illustrating how the term "translation" itself can serve to rebrand something else is to be found in the work of sociologists of the Scandinavian institutionalist school, who have started to drop the phrase "diffusion of ideas" and replace it by "translation of ideas" (see e.g. Bromley and Suárez 2014). In this way, they choose to stress the way that ideas change as they move from one place to another. So for these sociologists, the essence of "translation" is not that something remains invariant but that something changes, adapting to new circumstances.

\section{The hermeneutic as}


I now briefly consider a second aspect of conceptual innovation, which has to do with the exploitation of new metaphors and comparisons. All purely conceptual innovation, including the examples discussed above, has to do with interpretive hypotheses, not empirical ones. These are based on the hermeneutic 'as' (or one of its many variants, such as "in terms of"). The term comes originally from Heidegger (e.g. 1962: 186f), but the idea itself is ancient. In order to understand something new or complex, we typically try to see it as something more familiar. The hermeneutic as underlies all our definitions, classifications and metaphors. They have the form: X can be usefully interpreted as Y. Empirical hypotheses can be falsified if the evidence goes against them. Interpretive hypotheses, on the other hand, are assessed in terms of their usefulness, not in terms of truth. If I say that I see translations as bananas, you cannot prove that this is false, that I do not see them in this way. My interpretation remains possible at least for me. (For further discussion, see Chesterman 2008, and especially Føllesdal 1979.) When testing an interpretive hypothesis we ask: what is the use of it? What testable generalizations does it allow one to make? What new research questions might it facilitate? What consequences does it lead to (especially: what empirical consequences)? How does it compare with competing hypotheses? How strong are the arguments in favour, compared to those against? How might it change our way of thinking? What problem might it help to solve? (True, my bananas interpretation does not do well on such tests...)

Those aiming at conceptual innovation in TS sometimes propose a new as, but without really assessing its value and testing it pragmatically. So we have ever more translation metaphors, for instance. Some of these are very deeply ingrained in the TS community, such as seeing translation as transfer, i.e. as a kind of movement. But using this metaphor carries a cost in terms of problematic assumptions: for instance, the translation process does not actually "move" texts from A to B, but derives an additional, new text from a source, and the source usually remains where it was. (For a recent version of this argument, see e.g. Hill-Madsen and Korning Zethsen 2016; and for a useful discussion of some of the consequences of working with a given translation metaphor - in this case, metaphors of transfer and performance - see Cheetham 2016.) A good example of how different definitions of translation can be critically assessed can be found in Pym (2007). Several other fields have chosen to see other phenomena as translation examples can be found in Actor Network Theory, in biology and in chemistry, for instance. (See Gambier and van Doorslaer 2016.)

Some of this "seeing as" has to do with seeing a continuum as a set of discrete categories. Richard Dawkins (2004: 232), discussing the impossibility of drawing clear borders in palaeontology, laments what he calls "the tyranny of the discontinuous mind": our inbuilt tendency to think in terms of discrete entities rather than continua. In geology, for instance, there is currently a debate about whether or not we should say we are now living in an Anthropocene period, a terminological choice that would highlight the 
effects that human life and technology are having on the planet's climate, and thus perhaps help to shape human attitudes and behaviour. Even if there is a majority among geologists in favour of this innovation, there are still disagreements about when this new period can be said to have started. In TS, one good example of seeing a continuum as discrete chunks is to be found in Lance Hewson's work (2011) on translation criticism. Here, after going through a detailed analysis of a number of English translations of Flaubert's Madame Bovary and French ones of Jane Austin's Emma, Hewson places each translation in one of four categories based on the degree of difference-of-interpretational-effect compared to the original. He finds four to be a useful number of categories for this purpose, and indeed, why not? It allows a reasonable grouping of similarities and differences which sheds some light on the profiles of the different translations, and works well enough. However, he is well aware that the categories he positions along the continuum are not empirical facts, not natural categories, but interpretive, conceptual tools.

\section{Risky rhetoric}

Sometimes the rhetoric of an argument that sets out to make an innovative claim risks misleading readers about the status of the claim in question. For instance, a writer may present a conceptual claim in such a way that the reader may take it as an empirical one, in other words not as an interpretive opinion but as a factual truth. This misreading may come about only because the writer is using a kind of shorthand. For instance, the statement "there are two kinds of translation, A and B" is ultimately an interpretive hypothesis meaning ' $I$ think it is useful, for a given purpose, to see translations as falling into two types, for this allows us to analyse certain data in a meaningful way and to make significant generalizations'. It is not the case that these are the only two types that are ever recognized or relevant for any purpose, as universally accepted facts.

A misreading of this kind can also arise via the inappropriate use of factive verbs. These are verbs, in any language, whose meaning carries the shared assumption that a statement governed by such a verb is a true fact. English examples of such verbs are indicate, show, point out. "He pointed out that the Earth is round" states a well-known fact; but "he pointed out that the Earth is flat" sounds very strange today, ungrammatical even, because we know that this is not a fact. Non-factive verbs (such as English suggest, argue, claim) do not carry the assumption of being factually true, and so they allow disagreement. "He claimed that the Earth is flat" is a grammatically acceptable utterance, although we may doubt the sanity of the person referred to, as we retort “... but it isn't". All the examples in this section are in English, but I should underline that my point about this kind of risky rhetoric is by no means language-specific. 
Consider this example, from a recent article in Target, which I will anonymize: "NN points out that concepts are essentially 'theories about ontology'..." (emphasis added). But is this a fact, about what concepts are? Or rather an (interesting) interpretation concerning how we might consider them? Or a suggestion about categorizing concepts under some more general term ("theories")? Or an assumption about a standard definition (despite that slippery "essentially")? There are obviously many questions about interpretations of reality that can be discussed, but they are conceptual, philosophical or metaphysical arguments rather than empirical facts or standard definitions. This leads on to my next point.

Another risk of using loose rhetoric is to use a stipulative definition as if it were a lexical one. (For a detailed discussion of kinds of definition, also on the question of factual vs value-laden language, see Cattrysse 2014.) A stipulative definition is one that is not (or at least not yet) a dictionary or terminological standard, but one proposed by a given scholar or group as a working definition, useful for a given purpose at a given time, or indeed one proposed by a particular group for ideological reasons. In other words, such a definition is an interpretation that has pragmatic implications only for those that accept the interpretation. And here lies the problem: what happens if the interpretation is not accepted by everyone concerned? For those who prefer other interpretations, other definitions, no pragmatic consequences follow. Consider the current terrible situation in Syria: the various military policies involved depend on who is defined as a terrorist group, and there is more than one interpretation available. In TS, the sentence "translation is X" could easily be taken as a lexical definition, but this would be misleading if it is really intended as a stipulative one, to be glossed as 'I define translation as X, for present purposes (because...)'.

Readers may also be misled by descriptive statements that have the form of a definition but are not intended to be definitions at all. I was once criticized by a colleague for writing "Translation is something that people do with words". This is a totally inadequate definition, much too broad, I was told. But it was not intended as a definition but a partial description, in fact a categorization: translation can be placed in the general class of things that people do with words (and in many other classes too, of course).

In now mentioning a few more examples of such risky rhetoric I will keep the authors anonymous, as some are from unpublished work which I have seen as a referee, and I will mostly paraphrase rather than quote directly. My first example comes from a student who once emailed me, after reading my book about translation memes, asking whether I had "found" any new supermemes recently. She had presumably read my discussion of memes as if I had been presenting empirical discoveries rather than proposing hopefully useful metaphors (i.e. seeing ideas as memes and supermemes). 
An author regrets that some scholars "still resist" the post-structuralist view of meaning as something negotiated and interpreted rather than transferred - rather as if those who thus "resist" are comparable to the deluded souls who still resist the idea that the Earth is round. But the post-structuralist view is an opinion, not a factual, empirical truth, and as an opinion one can legitimately disagree with it. Another scholar might hold to a transfer view of meaning, at least in certain contexts, and for justifiable reasons. Yet another might argue that there are different kinds of meaning, some needing more interpretation and negotiation than others. One can weigh up the evidence in favour of one or another view, to be applied in a particular context for a particular purpose.

Someone else writes that we can "only" make sense of the world by construing it as narrative. But again, this is an opinion, not an empirical fact that is, or ought to be, universally accepted. Suppose someone is quite content to make sense of the world by construing it as a structure or a pattern? Like in the previous example, there is an uncomfortable implication here that the writer believes his own opinion to be the only correct one. But any hermeneutic as expresses a view, one possible way of seeing something.

A scholar appeals to a particular philosophy of language in support of a particular position, and argues that because of this philosophy, it follows that certain things should be done. But a philosophy, as an interpretive, conceptual structure, can only entail empirical consequences for those who accept this view (cf. the terrorist example above). The consequences are contingent on the degree of acceptance of the view in question. The writer's task, therefore, is to persuade readers that the view in question is reasonable and well justified, and better than alternatives.

A skopos critic argues that the skopos "should not" be seen as essential in the translation process. But when we are dealing with interpretations, the use of "should" is misleading. Anyone can, after all, see anything as anything, if they find it useful! Any combination of a should and a hermeneutic as is risky.

\section{Summing up}

Conceptual innovation means proposing new interpretive hypotheses. These need to be critically assessed, pragmatically: their actual or potential usefulness needs to be demonstrated, so that their added value as conceptual research tools is made clear. What kinds of generalizations, hypotheses or definitions would a proposed innovation enable? At what cost? What kinds of new research questions would it allow? What kinds of similarities or distinctions would we become more aware of? What problems would 
it help us to solve? How would the widespread adoption of the innovation affect the field's existing conceptual map? If the new proposal gains general acceptance, what social or economic consequences might there be? What losses?

And: let us write more carefully, avoiding risky rhetoric which may convey the impression that our conceptual tools are empirical facts. Our texts may contain many a hidden "as", many interpretations that need to be more carefully justified. It is not only other people's texts that we need to read more critically, but also our own.

\section{References}

Alvstad, Cecilia 2013. Voices in Translation. In Y. Gambier \& L. van Doorslaer (eds) Handbook of Translation Studies 4. Amsterdam/Philadelphia: John Benjamins, 207-210.

Bakhtin, M. M. 1981. Discourse in the novel. In M. Holquist (ed.) The Dialogic Imagination: Four Essays by M. M. Bakhtin. (Trans. C. Emerson \& M. Holquist.) Austin: University of Texas Press, $259-422$.

Bromley, Patricia \& Suárez, David 2015. Institutional theories and levels of analysis: diffusion, history and translation. In J. Schriewer (ed.) World Culture Recontextualized. London: Taylor and Francis, 139-160. Available at:

https://www.researchgate.net/publication/286246553 Institutional_Theories_and_Levels_of_Anal ysis_History Diffusion_and Translation. Last accessed 25.8.2017.

Carl, Michael, Bangalore, Srinivas \& Schaeffer, Moritz (eds) 2016. New Directions in Empirical Translation Process Research. Cham: Springer.

Cattrysse, Patrick 2014. Descriptive Adaptation Studies: Epistemological and Methodological Issues. Antwerp and Apeldoorn: Garant.

Cheetham, Dominic 2016. Literary translation and conceptual metaphors. From movement to performance. Translation Studies 9 (3), 241-255.

Chesterman, Andrew 2008. The status of interpretive hypotheses. In G. Hansen, A. Chesterman \& H. Gerzymisch-Arbogast (eds) Efforts and Models in Interpreting and Translation Research. Amsterdam/Philadelphia: John Benjamins, 49-61.

Cronin, Michael 2006. Translation and Identity. London/New York: Routledge.

Dawkins, Richard 2004. The Ancestor's Tale. London: Weidenfeld \& Nicolson.

Ellis, John M. 1993. Language, thought and logic. Evanston, IL: Northwestern University Press. 
Føllesdal, Dagfinn 1979. Hermeneutics and the Hypothetico-Deductive Method. Dialectica 33 (3-4), 319-336. Also in M. Martin and L.C. McIntyre (eds) 1994, Readings in the Philosophy of Social Science. Cambridge, MA.: MIT Press, 233-245.

Gambier, Yves 2008. Stratégies et tactiques en traduction et interpretation. In G. Hansen, A. Chesterman \& H. Gerzymisch-Arbogast (eds) Efforts and Models in Interpreting and Translation Research. Amsterdam/Philadelphia: John Benjamins, 63-82.

Gambier, Yves \& Munday, Jeremy 2014. A conversation between Yves Gambier and Jeremy Munday about transcreation and the future of the professions. Cultus: the Intercultural Journal of Mediation and Communication 7, 20-36.

Gambier, Yves \& van Doorslaer, Luc (eds) 2016. Border Crossings. Translation Studies and other disciplines. Amsterdam/Philadelphia: John Benjamins.

Grbić, Igor 2011. Translation vs. cislation: Should the reader be pampered or challenged? Programme and Book of Abstracts. The Sixth International Interdisciplinary Symposium "Encounter of Cultures” Novi Sad: Filozofski fakultet u Novom Sadu, Srbija, 1 December 2012: 52-60. Available via: https://www.google.fi/url?sa=t\&rct=j\&q=\&esrc=s\&source=web\&cd=1\&ved=0ahUKEwivmI7yoDVAhVCP5oKHRQ6BUUQFggoMAA\&url=http\%3A\%2F\%2Fbib.irb.hr\%2Fprikazi$\underline{\operatorname{rad} \% 3 F r a d \% 3 D 605389 \& u s g=A F Q j C N H k f K Z K g s i T r P w B 7 g h j s v a d 333 Q 1 Q ~ . ~ L a s t ~ a c c e s s e d ~}$ 25.8.2017.

Gumperz, John J. 1964. Linguistic and social interaction in two communities. American Anthropologist 66 (6 Part 2), 137-153.

Gutt, Ernst-August 1990. A theoretical account of translation - without a translation theory. Target 2 (2), $135-164$.

Gutt, Ernst-August 1991. Translation and Relevance. Cognition and context. Oxford: Blackwell. Halverson, Sandra 2015. Review of Kobut Marais (2014), Translation Theory and Development Studies: A Complexity Theory Approach. Translation Studies 8 (3), 365-368.

Heidegger, Martin 1962. Being and Time. (Trans. J. Macquarrie \& E. Robinson.) New York: Harper and Row.

Hernández Guerrero, Maria J. 2009. Traducción y periodismo. Bern: Peter Lang.

Hewson, Lance 2011. An Approach to Translation Criticism: Emma and Madame Bovary in Translation. Amsterdam/Philadelphia: John Benjamins.

Hill-Madsen, Aage, \& Zethsen, Karen Kornin 2016. Intralingual translation and its place within Translation Studies. Meta 61 (3), 692-708.

Holz-Mänttäri, Justa 1984. Translatorisches Handeln. Helsinki: Suomalainen Tiedeakatemia. House, Juliane 1981. A Model for Translation Quality Assessment. (Second edition.) Tübingen: Narr. 
Jakobson, Roman 1959. On linguistic aspects of translation. In R. Brower (ed.), On Translation. Cambridge, MA.: Harvard University Press, 232-239.

Jansen, Hanne \& Wegener, Anna 2013. Multiple Translationship. In H. Jansen \& A. Wegener (eds) Authorial and Editorial Voices in Translation: Collaborative Relationships between Authors, Translators, and Performers [Vita Traductiva 2]. Montreal: Éditions québécoises de l'œuvre, 142.

Kaindl, Klaus \& Spitzl, Karlheinz (eds) 2014. Transfiction: Research into the Realities of Translation Fiction. Amsterdam/Philadelphia: John Benjamins.

Koskinen, Kaisa 2014. Tampere as a translation space. Translation Studies, 7 (2), 186-202.

Kujamäki, Pekka \& Footit, Hilary 2016. Military History and Translation Studies. In Y. Gambier \& L. van Doorslaer (eds) Border Crossings. Translation Studies and other disciplines. Amsterdam/Philadelphia: John Benjamins, 49-72.

Lanstyák, István \& Heltai, Pál 2012. Universals in language contact and translation. Across Languages and Cultures 13 (1), 99-121.

Lewis, Gwyn, Jones, Bryn \& Baker, Colin 2012. Translanguaging: origins and development from school to street and beyond. Educational Research and Evaluation 18 (7), 641-654.

Mossop, Brian 2016. 'Intralingual Translation': A Desirable Concept? Across Languages and Cultures 17 (1), 1-24.

Nord, Christiane 1997. Translating as a Purposeful Activity. Manchester: St. Jerome Publishing.

Paloposki, Outi 2016. Translating and translators before the professional project. JoSTrans 25, 15-32.

Pérez-González, Luis 2014. Translation and new(s) media: Participatory subtitling practices in networked mediascapes”. In J. House (ed.) Translation: A Multidisciplinary Approach. Basingstoke: Palgrave Macmillan, 200-221.

Probirskaja, Svetlana 2017. 'Does anybody here speak Finnish?' Linguistic first aid and emerging translational spaces on the Finno-Russian Allegro train. Translation Studies 10 (3), 231-246.

Pym, Anthony 2007. On history in formal conceptualizations of translation. Across Languages and Cultures 8 (2), 153-166.

Reiß, Katharina \& Vermeer, Hans J. 1984. Grundlegung einer Allgemeinen Translationstheorie. Tübingen: Niemeyer.

Robinson, Douglas 2011. Translation and the Problem of Sway. Amsterdam/Philadelphia: John Benjamins.

Schreiber, Michael 1993. Übersetzung und Bearbeitung: Zur Differenzierung und Abgrenzung des Übersetzungsbegriff. Tübingen: Gunter Narr.

Simon, Sherry 2012. Cities in Translation: Intersections of Language and Memory. London/New York: Routledge. 
Taivalkoski-Shilov, Kristiina \& Suchet, Myriam (eds) 2013. La traduction des voix intra-textuelles / Intratextual Voices in Translation. Montréal: Éditions québécoises de l'œuvre.

Toury, Gideon 1995. Descriptive Translation Studies and Beyond. Amsterdam/Philadelphia: John Benjamins.

Ulrych, Margherita 2009. Translating and editing as mediated discourse: focus on the recipient. In R.

Dimitriu \& M. Shlesinger (eds) Translators and Their Readers. In Homage to Eugene A. Nida. Brussels: Editions du Hasard, 219-234.

Valdeón, Robert S. 2015. (Un)stable sources, translation and news production. Target 27 (3), 440-453.

Vihelmaa, Ella 2015. Kuusi merkitystä. Mistä lajienvälisessä kääntämisessä on kyse? [Six meanings. What is interspecific translation about?] TRACE: Finnish Journal for Human-Animal Studies 1, 24-61. Available at http://ojs.tsv.fi/index.php/trace/article/view/48383. Last accessed 25.8.2017.

Zethsen, Karen Korning 2009. Intralingual translation: An attempt at description. Meta 54 (4), 795-812. 